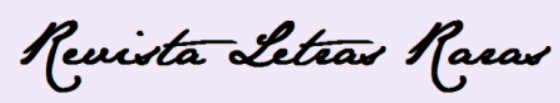

ISSN: 2317-2347 - Vol. 5, Ano 5, № 1 - 2016

\title{
As fronteiras midiáticas na comunidade surda
}

Janaína Pereira Claudio*

\begin{abstract}
Resumo: Este artigo tem por objetivo geral estimular as reflexões a respeito do estudo dos surdos em relação ao campo das Ciências da Comunicação acerca dos conceitos de cultura surda e cibercultura, analisando suas relações comprometidas em um processo global, onde as culturas, ciberculturas e comunidades estão envolvidas no movimento de um multiculturalismo contínuo. Neste contexto, partiremos da proposta de um estudo que enfoque as diferentes concepções de cultura e cibercultura, aproximando as teorizações de Martín-Barbero (2009) e García Canclini (2007) que relacionam a sistematização de mediação e de globalização. Investigaremos, também, a questão do modo de apropriação da comunidade surda, que promove a produção das fronteiras culturais nos processos comunicacionais e midiáticos, porém estabelecendo, principalmente, as tensões sociopolíticas, assim como os direitos e as lutas pela língua e pela diferença. Buscaremos uma leitura do quadro teórico, discutindo o modo como é possível apresentar a mídia vinculando a transformação social que ocorre nas comunidades surdas.
\end{abstract}

Palavras-chave: Cultura Surda. Cibercultura. Mediação. Mídia. Globalização.

\section{BORDERS MEDIA THE DEAF COMMUNITY}

\begin{abstract}
This article aims to stimulate reflections about the study of the deaf in relation to the field of science communication about the concepts of deaf culture and cyberculture, analyzing their relations involved in a global process, where cultures, cybercultures and communities are involved the motion of a continuous multiculturalism. In this context, we leave the proposal for a study that focuses on the different conceptions of culture and cyberculture, approaching the theories of Martin-Barbero (2009) and García Canclini (2007) relating to systematization of mediation and globalization. We investigate also the question of the deaf community ownership mode, which promotes the production of cultural barriers in communication and media processes, but establishing mainly socio-political tensions, as well as the rights and struggles for language and difference. We seek a reading of the theoretical framework, discussing how it is possible to present the media linking to social transformation which occurs in communities deaf.
\end{abstract}

Keywords: Deaf Culture; Cyberculture; Mediation; Media; Globalization.

\section{INTRODUÇÃO}

Estudar mídia é também investigar como definimos nosso próprio senso comum e quem somos. Silverstone (2011) afirma "que podemos começar a ver a tecnologia como

\footnotetext{
* Doutoranda pela PPGCC da UNISINOS, Linha de Pesquisa Cultura, Cidadania e Tecnologias da Comunicação (2013-2016). Mestre em Educação pela UFRGS (2010). Professora de Libras da Faculdade de Letras da Pontifícia Universidade Católica do Rio Grande do Sul (PUCRS), e-mail: janaina.claudio@pucrs.br.
} 


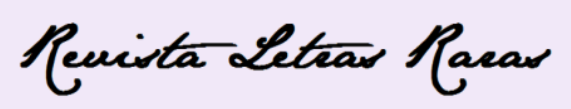

ISSN: 2317-2347 - Vol. 5, Ano 5, № 1 - 2016

cultura: ver que as tecnologias, no sentido que inclui não só o quê, mas também o como e o por que da máquina e seus usos, são objetos e práticas simbólicos e materiais, estéticos e funcionais.” (p. 50).

Portanto, dentro desse pensamento, podemos observar as investigações de estudos que analisaram a maneira como a mídia participa em nossas vidas, social e culturalmente falando. De acordo com Silverstone (2011, p.16), "precisaremos examinar a mídia como um processo", dentro do qual os sujeitos são obrigados a se comunicar, a se informar. Considerando a complexidade dessa conceituação de mídia, ela também é entendida como ambiente, isto é, num âmbito que ultrapassa a ideia de "meios de comunicação".

Nesse sentido, é essencial compreender o papel da mídia, especialmente das tecnologias de mídia e de comunicação que, justamente, neste contexto, estão acompanhadas do poder da transformação política e econômica que empregam as mudanças sociais. $\mathrm{O}$ autor Silverstone (2011, p. 61) esclarece que "precisamos saber como a mídia trabalha: o que nos oferece e como".

Os sujeitos contemporâneos, para estar atualizados e comunicar-se entre si, buscam consumir os diversos elementos midiáticos. Diante dessa realidade, o desafio é criar no sistema social e cultural, um modo de conexão das informações entre as mídias e os sujeitos, de maneira sistemática e universal, usando como reforço a afirmação do pesquisador McLuhan (2007, p. 21), que disse que "o meio é a mensagem".

Os fluxos de produção cultural da contemporaneidade são motivados pelo ambiente criado pelas mídias, em especial, a internet. A fronteira midiática dentro deste contexto, o das relações de poder por meio do uso da internet, se apresenta como um espaço de produção cultural que permite conectar as diversas identidades culturais. Dessa forma, a produção cultural na fronteira midiática é entendida a partir de um espaço de circulação de idiomas, costumes, tradições, sujeitos, comunidades, histórias, religiões e outros.

Raddatz (2011) descreve que:

nas fronteiras culturais, o local e o regional não desaparecem, mas assumem outra característica que deixa à mostra uma fronteira pontilhada de manifestações oriundas das formas identitárias entre as nações. Não são identidades, mas identificações que se mostram a partir das "mediações comunicativas de cultura" (RADDATZ, 2011, p. 2). 


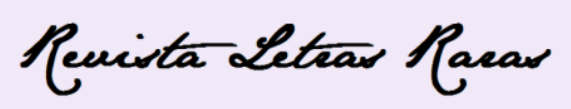

ISSN: 2317-2347 - Vol. 5, Ano 5, № 1 - 2016

Deste ponto de vista, as articulações para a construção da cultura pelos sujeitos, são estabelecidas a partir das mediações comunicativas de cultura, que as fronteiras permitem de uma forma mais ampla para a interação e a comunicação na midiatização.

Nessa linha de compreensão, a pesquisadora Pereira (2010) em sua tese de doutorado, tem pensado assim a relação entre comunicação e cultura na sociedade contemporânea:

as articulações entre a comunicação e a cultura também reforçam a ideia de uma sociedade multicultural, marcada por intensos fluxos migratórios e pela promoção da polietnicidades, questionando as políticas assimilacionistas e enfatizando a diferença cultural como problemática da cidadania contemporânea. (PEREIRA, 2010, p. 41).

Nessa perspectiva, a autora ancora seu desafio sobre o discurso de multiculturalismo, noção adotada pela autora Cortina (2005) que enfoca a sistematização da diversidade cultural. Para esclarecer a ideia de multiculturalismo, podemos dizer que a sociedade multicultural é entendida como "um conjunto variado de fenômenos sociais, que derivam da difícil convivência e/ou coexistência, em um mesmo espaço social, de pessoas que se identificam com culturas diferentes." (CORTINA, 2005, p. 140).

\section{Cultura surda}

O que é a cultura surda? Qual a importância de que esta seja formada pelos sujeitos surdos? O que a mídia pode evidenciar a respeito dos artefatos culturais das pessoas surdas? São questões que proponho trazer neste subcapítulo, além de apresentar as perspectivas sobre o entendimento do que é realmente a cultura surda para os surdos.

Nos estudos e pesquisas científicas sobre a cultura, percebem-se variações de significados, desde concepções a contextualizações históricas. E o conceito de cultura é uma questão bastante discutida e investigada por diversas áreas - antropologia, sociologia, literatura, educação, entre outras. A cultura, que é um conceito complexo, pode ser compreendida como um conjunto de formas e expressões que caracterizam o tempo de uma sociedade determinada.

E nesse campo a Cultura pode ser tida como conjunto de formas e expressões que compreende costumes, crenças, regras, normas e maneiras de ser e de como a sociedade se 


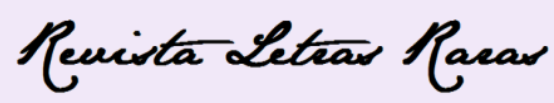

ISSN: 2317-2347 - Vol. 5, Ano 5, № 1 - 2016

comporta. A autora Cortina (2005, p. 148) vê a cultura como "conjunto de modelos de pensamento e de conduta que dirigem e organizam as atividades e produções materiais e mentais de um povo, em sua tentativa de adaptar o meio em que vive a suas necessidades, e que pode diferenciá-lo de qualquer outro". Assim, a cultura é também criação e um fator de humanização, além de ser definida como dinâmica e complexa.

Strobel (2013) entende que:

a cultura é uma ferramenta de transformação, de percepção, da forma de ver diferente, não mais de homogeneidade, mas de vida social constitutiva de jeitos de ser, de fazer, de compreender e de explicar. Essa nova marca cultural transporta para uma sensação a cultura grupal, ou seja, como ela diferencia os grupos, no que faz emergir a "diferença" (STROBEL, 2013, p. 23).

Assim, para entender as identificações culturais ou sistemas de representações, a pesquisadora procurou apresentar um conjunto de reflexões sobre a própria identidade cultural e sobre a identidade cultural do outro. De acordo com essa exposição, a identidade cultural está relacionada ao desenvolvimento da mediação comunicativa na globalização e, portanto, pode ser vista como capaz de criar significados, de integrar as diferentes identidades, produzindo, desta forma, a identificação das características culturais do indivíduo/sujeito e da coletividade da qual faz parte.

Pensar a discussão sobre a diferença cultural de pessoas surdas passa por uma comparação entre surdos e ouvintes. Essa perspectiva faz parte de um processo social que contém um discurso de desigualdade, de falta de direitos, de falta de vozes sonoras, de proibição de votar, de proibição de casar, e que são lutas incansáveis para representar na sociedade, ao longo do tempo, um único objetivo - o de ser cidadão surdo. Portanto, os sujeitos da comunidade surda acolhem suas tribos como minorias linguísticas, onde a cultura surda seja relacionada às práticas e às interações sociais da sua língua.

Nesse sentido, as culturas minoritárias, como o grupo de pessoas surdas, têm travado uma luta para que as culturas majoritárias percebam as diferenças culturais. $\mathrm{E}$ a educação para surdos, por exemplo, tem um grande papel dentro da escola, pois o trabalho dos professores é mostrar que os surdos podem ser vistos como pessoas diferentes e não como incapacitados ou deficientes, como muitas vezes são chamados. As características dos surdos, mais apontadas, sempre foram as que evidenciavam pontos negativos, e para Skliar (1998) o discurso da 


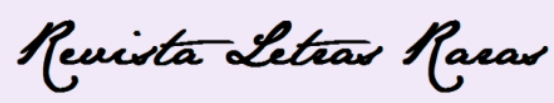

ISSN: 2317-2347 - Vol. 5, Ano 5, № 1 - 2016

diferença está pressionado pela visão clínica, sob o recorte da falta da fala e da audição que transforma o silêncio em anormal.

Importante esclarecer aqui que minorias linguísticas são aquelas que se comunicam por meio de uma língua diferente da língua da maioria da população ou da adotada pelo País. A Língua Brasileira de Sinais (LIBRAS), a usada pelos surdos, uma evidente minoria linguística, foi oficializada pela Lei $n^{\circ} 10.436$, de 24 de abril de 2002, embora essa língua já existisse há muitos anos. E a sua oficialização, a partir daquele ano, possibilitou a expansão das vantagens e das obrigações em relação aos direitos desse grupo, como cidadania, comunicação, cultura e identidade.

Quanto às raízes históricas das línguas de sinais, para Sacks (2010), estas línguas existem desde o surgimento da língua oral humana, e permanecerão enquanto surdos habitarem o mundo. Já Stokoe, em 1960, “percebeu e comprovou que a língua dos sinais atendia a todos os critérios linguísticos de uma língua genuína, no léxico, na sintaxe e na capacidade de gerar uma quantidade infinita de sentenças" (QUADROS; KARNOPP, 2004, p. 30). Portanto, a Língua Brasileira de Sinais (LIBRAS), língua materna dos surdos, representa o sistema linguístico dos surdos, traz respeito ao direito da minoria linguística e fundamenta a luta pelo direito ao intérprete de Libras nos lugares públicos.

Com base na minha experiência pessoal, fui registrando minha trajetória com a comunidade surda. Nesse tempo conheci a posição política das lutas pelo direito dos surdos, espalhados pelo Brasil e no mundo, à escola e ao emprego. E essas lutas foram as grandes responsáveis pela ampliação dos questionamentos apresentados pelos sujeitos comunicantes surdos, no campo da comunicação. E fui aumentando minha consciência, ao longo do tempo, sobre o surgimento dos movimentos de resistência surda contra a dominação imposta em outras relações aos cidadãos surdos. Eram lutas contra uma sociedade predominantemente ouvinte, na qual desde o final do século XIX até os anos de 1970, os surdos foram obrigados a comportarse como se fossem pessoas ouvintes - o movimento denominado ouvintismo ${ }^{1}$.

Nesta perspectiva, surge o processo de desouvintização, no qual a proposta era a valorização das produções culturais surdas, da língua de sinais e da comunidade surda, além de evidenciar um sistema de valores de visualidades. Nesse exercício político, os membros da comunidade surda foram os principais responsáveis por mostrar as diferenças entre o deficiente

\footnotetext{
${ }^{1}$ Conceito utilizado pelo autor SKLIAR (1998).
} 


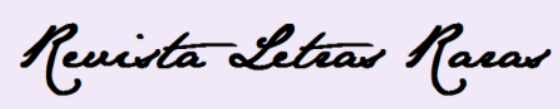

ISSN: 2317-2347 - Vol. 5, Ano 5, № 1 - 2016

e o diferente, e pelas tentativas de colocar nas discussões nacionais de saúde e de educação, as pautas da cidadania comunicativa surda.

Conhecer as lutas dos surdos e delas fazer parte, levou-me a concordar com o que dizem Lopes; Veiga-Neto (2010),

ter o próprio surdo como o outro significa buscar nele a possibilidade de que ele mesmo sirva como referente, capaz de informar, àquele que olha e se olha, sobre (o que é) a condição de ser surdo. Fundamentados em Foucault (1995), vemos o olhar-se e o narrar-se como práticas necessárias para o processo de subjetivação; são práticas que permitem ao indivíduo desenvolver a sua sujeição ao grupo que o descreve e o informa. Romper com olhar ouvinte, que aparece fortemente marcado nas histórias e narrativas surdas, é uma das ações para que a surdez saia do campo oposicional surdo/ouvinte, para ser considerada e reafirmada no próprio campo surdo (LOPES; VEIGA-NETO, 2010, p. 121).

Nesse sentido, é assim que o surdo passa, ao outro surdo, a sua história, por gerações para que, por meio das narrativas surdas, sejam contados seus valores, costumes e lutas. Nisso está o poder de existir e de reconhecer a língua, a comunidade e a cultura surdas.

A autora Lopes (1998) entende que o surdo começa a ser visto como um sujeito cultural nas experiências com outras pessoas surdas:

Pensando na perspectiva dos "diferentes na diferença", o surdo passa a ser um sujeito cultural produtor e produto de subjetividades conjugadas, e a escola, como em qualquer situação, independente de ser para surdos ou não, pode ser vista como um meio disciplinador de corpos, línguas e mentes. (LOPES, 1998, p. 112)

E as diferenças culturais são produzidas por meio das formas com que elas marcam os seus territórios: pelo povo, pela identidade, pela língua, pelo direito e pela comunidade.

Sobre o tema, assim, Skliar (1998) se coloca:

A diferença, como significação política, é construída histórica e socialmente; é um processo e um produto de conflitos e movimentos sociais, de resistências às assimetrias de poder e de saber, de uma outra interpretação sobre a alteridade e sobre o significado dos outros no discurso dominante (SKLIAR, 1998, p. 6). 


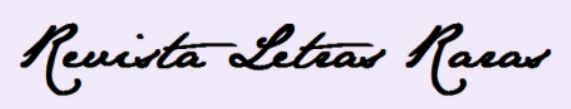

ISSN: 2317-2347 - Vol. 5, Ano 5, № 1 - 2016

Desse modo, no tocante à diferença, podemos compreender que essa noção na cultura surda implica refletir sobre práticas sociais, relacionando ao uso da língua de sinais, por meio de comunicação visual e espacial, o direito à língua materna. Neste universo, podemos perceber que o sujeito surdo é também colocado em relação aos discursos dominantes, que fazem parecer a cura da audição e da fala, em relação à surdez, como mudança necessária a um corpo estranho.

Do ponto de vista do sujeito é a cultura que promove a identificação do humano consigo mesmo, com seus valores, direitos, costumes, línguas e crenças. Nesse sentido, podemos dizer que a cultura é a base sobre a qual a subjetividade do indivíduo está defendida, em primeiro lugar, pelo reconhecimento na própria pessoa.

\section{Cibercultura}

A noção de cibercultura implica pensar as relações desde o campo sociocultural, a mídia e o cidadão, onde os sujeitos são estimulados a produzir, se apropriar, distribuir e compartilhar informações. São as expansões da cibercultura que consideram fundamental o compartilhamento, a distribuição e a apropriação dos bens simbólicos. Para compreender melhor a definição da noção de cibercultura, veremos um pouco do que dizem os autores Lévy (1999), Rifiotis (2012) e Lemos (2013).

Vamos conhecer os conceitos de ciberespaço e cibercultura, no qual o pesquisador Lévy (1999) embasa o entendimento sobre o espaço a ser investigado:

Como uso diversas vezes os termos "ciberespaço" e "cibercultura", parece-me adequado defini-los brevemente aqui. O ciberespaço (que também chamarei de "rede") é o novo meio de comunicação que surge da interconexão mundial dos computadores. O termo especifica, não apenas a infraestrutura material da comunicação digital, mas também o universo oceânico de informações que ela abriga, assim como os seres humanos que navegam e alimentam esse universo. Quanto ao neologismo "cibercultura", especifico aqui o conjunto de técnicas (materiais e intelectuais), de práticas, de atitudes, de modos de pensamento e de valores que se desenvolvem juntamente com o crescimento do ciberespaço. (LÉVY, 1999, p. 17).

Assim, o movimento social e a cultura se apresentam relacionados aos dois termos anteriormente explicitados: ciberespaço e cibercultura. Esses dois conceitos são permeados pela 


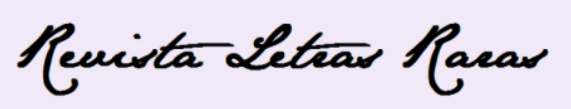

ISSN: 2317-2347 - Vol. 5, Ano 5, № 1 - 2016

navegação, pela programação e pela realidade digital usada pelos seres humanos para se comunicar em comunidade.

Rifiotis (2012) conta a sua experiência sobre o estudo de cibercultura:

No campo dos estudos da "cibercultura", a vontade do saber sociotécnico está expressa nas descrições dos modos de "iniciação" ou "socialização" dos "usuários", e nas possibilidades que tais descrições abrem para a compreensão das modalidades de "apropriação" ou "representação", entre outras palavraschave correntes nos nossos trabalhos. É assim que a descrição da plataforma (sempre presente e com lugar de destaque) é entendida como uma apropriação pelos sujeitos. (RIFIOTIS, 2012, p. 572).

O campo dos estudos de cibercultura se situa no cenário do sistema sociotécnico em formação. Concretamente, defendo a ideia de uma posição crítica em relação à noção no campo da cibercultura, tal como "uso" e "apropriação" envolvendo os objetos técnicos. Nessa perspectiva sociotécnica é que vou desenvolver meus argumentos sobre cibercultura surda na futura qualificação de tese.

Lemos (2013) aprofunda o pensamento sobre os dois termos utilizados e discutidos ao longo dos anos:

\begin{abstract}
A cibercultura vai se caracterizar pela formação de uma sociedade estruturada através de uma conectividade telemática generalizada, ampliando o potencial comunicativo, proporcionando a troca de informações sob as mais diversas formas, fomentando agregações sociais. O ciberespaço cria um mundo operante, interligado por ícones, portais, sítios e home pages, permitindo colocar o poder de emissão nas mãos de uma cultura jovem, tribal, gregária, que vai produzir informação, agregar ruídos e colagens, jogar excesso ao sistema. (LEMOS, 2013, p. 88).
\end{abstract}

Com o fenômeno dos estudos da cibercultura e do ciberespaço, é interessante perceber a necessidade de se repensar categorias de um conhecimento intelectual. Em particular, a mídia é o ninho da união civil da ciência com a técnica. Podemos entender, portanto, que o conceito de cibercultura está relacionado à interação entre sociedade, cultura e tecnologias, isto é, a cultura contemporânea associada às mídias (tecnologias digitais). E no ciberespaço podemos compreender que com apenas um clique na tecla ou no teclado é permitido acessar e conectar diversas pessoas e lugares, e também, formar comunidades ou grupos. Logo, podemos observar que a cibercultura se caracteriza pela integração da sociedade com a técnica. 


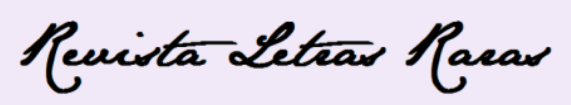

ISSN: 2317-2347 - Vol. 5, Ano 5, № 1 - 2016

Por essa razão, Lemos (2003) entende que:

A sociabilidade pós-moderna, por colocar ênfase no presente, não investe mais no dever ser, mas naquilo que é, no presente. A vida quotidiana contemporânea vai insistir na dimensão do presente; num presente caótico e politeísta em detrimento de perspectivas futuristas. (LEMOS, 2003, p. 89).

É interessante comentar que, para os indivíduos/sujeitos contemporâneos, em referência à sociabilidade, o ambiente digital que é percebido como um recurso socialmente potencializado é, também, como um alimento para o povo na cibercultura.

Nesse sentido, podemos entender os modos de conhecimentos trazidos pela cibercultura, referindo-nos às tecnologias que permitem que os grupos e os indivíduos compartilhem e negociem os modelos mentais que trazem como resultado um aumento da inteligência coletiva.

De fato, a nossa memória visual de longo tempo pode armazenar, em termos de informação e de conhecimento adquirido com o uso da internet e outras mídias, como a televisão, jornal e demais, o equivalente ao que cabe num chip. Por outro lado, Lévy (1999, p. 167) afirma que "esse ideal da inteligência coletiva passa, evidentemente, pela disponibilização da memória, da imaginação e da experiência, por uma prática banalizada de troca dos conhecimentos, por novas formas de organização e de coordenação flexível e em tempo real".

Desta forma, podemos afirmar que os indivíduos quando encontram em certo grupo, a coletividade, eles acabam compartilhando as trocas de informação e de conhecimento, formando uma nova estratégia para formar o sistema de organização social. As pessoas surdas, nas comunidades surdas digitais, buscam as memórias visuais para se manter informadas, como os vídeos, as imagens e os textos curtos. É uma alternativa para que essas comunidades continuem compartilhando as informações no ambiente digital e construindo outro sistema de comunicação.

\section{Mediação comunicativa surda na globalização}

Ao analisar o estudo da comunicação a partir da cultura, Martín-Barbero (2009) foca nas mediações, etapa de ideologias, que se articulam entre matrizes culturais sem semelhanças 


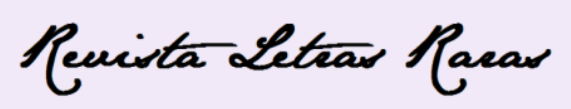

ISSN: 2317-2347 - Vol. 5, Ano 5, № 1 - 2016

por intermédio dos meios, os sujeitos e os cotidianos familiar, escolar e outros. Nas esferas do processo de comunicação, o pensamento inicial proposto por Martín-Barbero em sua obra, "Dos meios às mediações", leva os leitores a refletir que as mediações comunicativas da cultura foram pensadas em diferentes campos de pensar e de compreender. Martín-Barbero (2009) disse que "pensar os processos de comunicação neste sentido, a partir da cultura, significa deixar de pensá-los a partir das disciplinas e dos meios. Significa romper com a segurança proporcionada pela redução da problemática da comunicação à das tecnologias" (MartínBarbero, 2009, p. 287).

Também é fundamental a concepção de Martín-Barbero (2009), pois realiza um convite para refletir sobre o mapeamento da comunicação e das diferentes culturas. Com este olhar, o pesquisador/leitor pode pensar as culturas como diferentes espaços: tribos, bairros, países, comunidades surdas e outros territórios.

Martín-Barbero (2009) fala ainda que:

A luta por habitação, pelo fornecimento de energia elétrica e água, por um transporte básico e por um mínimo de atenção à saúde se inscreve numa realidade mais integral, a da luta pela identidade cultural. Numa sociedade tão pouco institucionalizada, as associações populares - desde os mutirões e os restaurantes populares de bairro até os centros de educação - "vão construindo um tecido social que vai desenvolvendo uma nova institucionalidade, fortalecendo a sociedade civil, apresentando traços de novas relações sociais e de sujeitos coletivos na vida do país" (MARTíN-BARBERO, 2009, p. 274).

Portanto, as interpretações selecionadas sobre cultura e cultura surda, que ocorrem nas disputas pelo poder, pela dominação e pela língua, considerados nos ambientes sociais como na educação, na comunicação, na sociedade e na família, apontam a necessidade de se criar laços afetivos que respeitem e aceitem a língua visual (a língua de sinais) desses sujeitos surdos como cidadania comunicativa.

No tocante à comunicação digital e o sujeito surdo no mundo das mídias, a internet oferece uma grande vantagem para as pessoas surdas. São os recursos visuais, como animação de imagens coloridas e imagens gráficas, que estimulam o interesse pelo seu uso, visto que a linguagem pela qual os surdos se comunicam é a visual.

A minha maior curiosidade no ambiente digital é a conversa pela internet, pois quando uma pessoa surda navega, se conecta ao mundo digital, e pode participar das redes sociais que 


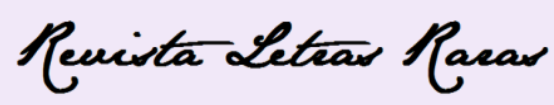

ISSN: 2317-2347 - Vol. 5, Ano 5, № 1 - 2016

oferecem chats e comentários (bate-papos digitais), onde são percebidas na dimensão da diversidade de informações e de pessoas que se encontram na rede, sem, no entanto, sofrer qualquer categoria de discriminação por ser surdo. Para os autores Rosa \& Cruz (2001), que publicaram o artigo sobre o uso da internet como fator de inclusão da pessoa surda, "para os surdos, isto é inserção: é poder ser surdo, sem ser discriminado, ou sem ser excluído de um mundo sonoro" (p. 43).

A esfera da globalização surge do diálogo com a antropologia, a sociologia, a economia. O pesquisador, García Canclini (2007) entende que "a globalização pode ser vista como um conjunto de estratégias" (p. 29), por meio dos fluxos de pessoas e das comunicações, que sempre acompanham todas as coisas em movimento com as representações culturais e sociais, pois "hoje em dia estamos todos em movimento." (BAUMAN, 1999, p. 85). Nesse sentido, a globalização é organizada, em alguns aspectos, por meios de comunicação, da aceleração da internet, do crescimento cultural e do econômico que funcionam em toda parte.

Na perspectiva antropológica, a identidade cultural é flexível, adaptável às novidades que a globalização e outros movimentos que possam apresentar por seus fluxos nos meios da comunicação, pois com eles são capazes de englobar novos significados, podendo ser imagens de outras culturas e também outras identidades, sem perder suas origens.

No entanto, há possibilidade de se observar a diversidade construída pela globalização, na convivência das diversas culturas por meio da adaptação de elementos de outras tantas. García Canclini (2007) afirma que "a globalização unifica e interliga, mas também "estaciona” de um modo diferente em cada cultura.” (p. 168). Dessa forma, destaco a importância crescente dos compartilhamentos de significados, símbolos e imagens, impulsionados pela globalização, que por meio dos meios de comunicação e da mídia têm a capacidade de atingir os sujeitos que fazem contatos nas redes da internet, com novos elementos das diferentes culturas.

Vale lembrar que na noção geopolítica de nacionalidade, a cultura é afetada pela ação dos recursos tecnológicos utilizados pelos humanos tanto na produção da economia, do comércio quanto na circulação da comunicação e da informação. Percebe que "a infraestrutura tecnológica que dá um suporte à globalização, viabiliza um nível e uma diversidade de trocas e de conhecimento entre nações e culturas nunca antes experimentados, mudando as relações e práticas econômicas, sociais e culturais entre Estados e suas populações" (BAUDRILLARD, 1970, p. 44). 


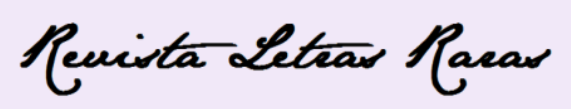

ISSN: 2317-2347 - Vol. 5, Ano 5, № 1 - 2016

Nessa perspectiva, Hall tenta refletir sobre como devemos pensar a identidade nas mudanças da globalização. Sobre isso ele diz que:

O que é importante para nosso argumento quanto ao impacto da globalização sobre a identidade é que o tempo e o espaço são também as coordenadas básicas de todos os sistemas de representação. Todo meio de representação escrita, pintura, desenho, fotografia, simbolização através da arte ou dos sistemas de telecomunicação - deve traduzir seu objeto em dimensões espaciais e temporais. (HALL, 2006, p. 70).

E o autor confirma que "todas as identidades estão localizadas no espaço e no tempo simbólicos" (HALL, 2006, p.71). Elas possuem suas paisagens, seus lares, suas casas e seus territórios geográficos, como suas localizações no tempo, no espaço e nas gerações históricas estão vinculados no passado e no presente.

\section{CONSIDERAÇÕES PROVISÓRIAS}

Fundamentalmente, a perspectiva deste artigo, apresenta que a comunicação é essencial para todos os seres vivos em todas as esferas da vida planetária. Portanto, a mídia como a tecnologia, especificamente, a internet, apresentam uma forma de comunicação mediada por dispositivo digital e tecnológico. Com o avanço dessas mídias, as pessoas passaram a ter uma vida mais útil e com mais informações do que antigamente. De fato, com a chegada da internet, a vida dos sujeitos surdos, com as suas interações sociais e digitais, passou a ser de mais independência, pois podem acessar e procurar as informações com mais facilidade.

Primo (2003) argumenta que "a interação não deve ser vista como uma característica do meio, mas como um processo desenvolvido entre os interagentes" (p. 8). E a Comunidade Surda vem lutando pela ampliação da utilidade da comunicação visual mediada na internet, para que esta seja relacionada com as ações políticas, sociais, educacionais e culturais. Essas ações manifestam, ainda, os assuntos comunitários voltados para a questão de emprego, de qualidade de vida e demais perspectivas. Portanto, os sujeitos surdos devem enfocar, principalmente, o compartilhamento do conhecimento sobre os diversos assuntos e seguir 


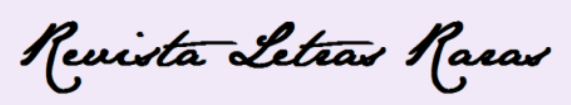

ISSN: 2317-2347 - Vol. 5, Ano 5, № 1 - 2016

construindo o processo em andamento para que a sociedade raciocine de forma mais respeitosa acerca do seu espaço digital e da acessibilidade à comunicação visual.

\section{REFERÊNCIAS}

BAUDRILLARD, J. A sociedade do consumo. Lisboa: Edições 70, 1970. Disponível em: http://www.maxwell.vrac.puc-rio.br/16030/16030_4.pdf Acesso em: 15 abr. 2016.

BAUMAN, Z. Globalização: as consequências humanas. Tradução Marcus Penchel. Rio de Janeiro: Jorge Zahar, 1999.

BRASIL. Lei $n^{\circ} 10.436$, de 24 de abril de 2002. Dispõe sobre a Língua Brasileira de Sinais Libras e dá outras providências. Brasília, $181^{\circ}$ da Independência e $114^{\circ}$ da República.

CORTINA, A. Cidadãos do mundo para uma teoria da cidadania. Tradução Silvana Cobucci Leite. São Paulo: Loyola, 2005.

GARCÍA CANCLINI, N. A globalização imaginada. Tradução Sérgio Molina. São Paulo: Iluminuras, 2007.

HALL, S. A identidade cultural na pós-modernidade. Tradução Tomaz Tadeu da Silva, Guacira Lopes Louro. 11. ed. Rio de Janeiro: DP\&A, 2006.

LEMOS, A. Cibercultura: tecnologia e vida social na cultura contemporânea. 6. ed. Porto Alegre: Sulina, 2013.

; CUNHA, P. (orgs.) Olhares sobre a cibercultura. Porto Alegre: Sulina, 2003.

LÉVY, P. Cibercultura. São Paulo: 34, 1999.

LOPES, M. C. Relações de poderes no espaço multicultural da escola para surdos. In: SKLIAR, C. (Org.) A surdez: um olhar sobre as diferenças. Porto Alegre: Mediação, 1998, p. 105 -122.

; VEIGA-NETO, A. Marcadores culturais surdos. In: VIEIRA-MACHADO, L. M. da C.; LOPES, M. C. (Orgs.) Educação de surdos: políticas, línguas de sinais, comunidade e cultura surda. Santa Cruz do Sul: UNISC, 2010.

MARTÍN-BARBERO, J. Dos meios às mediações: comunicação, cultura e hegemonia. Tradução Ronald Polito, Sérgio Alcides. Rio de Janeiro: UFRJ, 2009.

MCLUHAN, M. Os meios de comunicação como extensões do homem. Tradução Décio Pignatari. São Paulo: Cultrix, 2007.

PEREIRA, C. R. A. Processos comunicacionais kaingang: configurações e sentidos da identidade cultural, memória e mídia em perspectiva histórica, São Leopoldo, 2010. Tese (Doutorado em Ciências da Comunicação), Universidade do Vale do Rio dos Sinos, UNISINOS.

PRIMO, A. F. T. Enfoques e desfoques no estudo da interação mediada por computador. In: Proceedings of Intercom 2003, XXVI Congresso Brasileiro de Ciências da Comunicação. Belo Horizonte, 2003. 


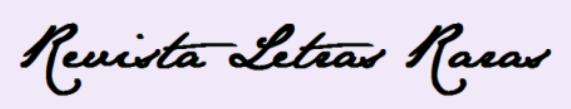

ISSN: 2317-2347 - Vol. 5, Ano 5, № 1 - 2016

QUADROS, R. M. de; KARNOPP, L. B. Língua de sinais brasileira: estudos linguísticos. Porto Alegre: Artmed, 2004.

RADDATZ, V. L. S. Produção cultural na mídia fronteiriça Brasil-Argentina. In: III Colóquio Brasileiro de Ciências da Comunicação, Recife, set. 2011. Disponível em: http://www.intercom.org.br/papers/nacionais/2011/resumos/R6-2147-1.pdf Acesso: 15 abr. 2016.

RIFIOTIS, T. Desafios contemporâneos para a antropologia no ciberespaço: o lugar da técnica. Civitas Revista de Ciências Sociais, Porto Alegre, v. 12, n. 3, set.-dez., 2012, p. 566-578.

ROSA, A. da S.; CRUZ, C. C.. Internet: fator de inclusão de pessoa surda. Revista Online da Biblioteca Prof. Joel Martins, Campinas, v.2, n.3, jun. 2001, p.38-54.

SACKS, O. Vendo vozes: uma viagem ao mundo dos surdos. Tradução Laura Teixeira Motta. São Paulo: Companhia das Letras, 2010.

SKLIAR, C. Um olhar sobre o nosso olhar acerca da surdez e as diferenças. In: SKLIAR, C. (Org.) A surdez: um olhar sobre as diferenças. Porto Alegre: Mediação, 1998, p. 5-32.

SILVERSTONE, R. Por que estudar a mídia? Tradução Milton Camargo Mota. São Paulo: Loyola, 2011.

STROBEL, K. As imagens do outro sobre a cultura surda. Florianópolis: Editora UFSC, 2013.

Recebido em: 30/04/2016

Aceito em: 30/06/2016 